HIAS-E-13

\title{
The First Arrow Hitting the Currency Target: A Long-run Risk Perspective
}

Takashi Kano

Hitotsubashi University, Tokyo Center for Economic Research, Japan

Kenji Wada

Hitotsubashi University

November 9, 2015

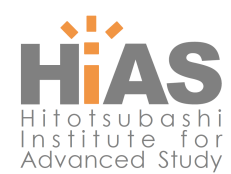

Hitotsubashi Institute for Advanced Study, Hitotsubashi University 2-1, Naka, Kunitachi, Tokyo 186-8601, Japan

tel:+81 425808604 http://hias.ad.hit-u.ac.jp/

HIAS discussion papers can be downloaded without charge from: http://hdl.handle.net/10086/27202

https://ideas.repec.org/s/hit/hiasdp.html

All rights reserved. 


\title{
The First Arrow Hitting the Currency Target: A Long-run Risk Perspective
}

\author{
Takashi Kano ${ }^{\dagger}$ Kenji Wada \\ ${ }^{\dagger}$ Hitotsubashi University, Tokyo Center for Economic Research, Japan \\ ${ }^{\ddagger}$ Hitotsubashi University
}

Current Draft: November 9, 2015

\begin{abstract}
This paper reconsiders the successful currency outcome of the first arrow of the Abenomics. The Japanese yen depreciation against the U.S. dollar after the introduction of the first arrow comoves tightly with long-term yield differentials between Japan and the United States. The estimated term structure of the sensitivity of the currency return of the Japanese yen to the two-country interest rate differential indeed shifts up and becomes steeper after the onset of the Abenomics. To explain this structural change in the term structure of the Fama regression coeffiient, we employ a long-run risk model endowed with real and nominal conditional volatilities as in Bansal and Shaliastovich (2013). Under a plausible calibration, the model replicates the structural change when nominal uncertainty dominates real uncertainty in the U.S. bond market. We conjecture that the arrow was shot off from the U.S. side, not the Japan side.
\end{abstract}

Key Words : Japanese yen/U.S. dollar exchange rate; Term structure; Fama regression; Long-run risk; Abenomics

JEL Classification Number : E31, E37, F41

\footnotetext{
$\dagger$ The first author wishes to thank a grant-in-aid for scientific research from the Japan Society for the Promotion of Science (number 24330060) and financial support from Hitotsubashi Institute for Advanced Study.

${ }^{\dagger}$ Contacting address: Graduate School of Economics, Hitotsubashi University, Naka 2-1, Kunitachi-city, Tokyo, 186-8601, Japan. Emails: tkano@econ.hit-u.ac.jp (T.Kano), 2112279c@g.hit-u.ac.jp (K.Wada)
} 


\section{Introduction}

One of the most striking events that international financial markets recently encountered might be the sharp depreciation of the Japanese yen (JPY) against the U.S. dollar (USD) started at the end of 2012. Since 78.97 JPY/USD was recorded on October 2012, the JPY keeps depreciating to 123.17 JPY/USD by August 2015. The depreciation rate of the JPY within the two-year window is $56.0 \%$. Given the prolonged appreciation of the JPY against the USD after the Lehman shock and the subsequent global financial crisis (GFC), the change in the direction of one of the major currencies was so drastic that identifying a fundamental source behind the rapid JPY depreciation is a serious challenge for researchers of exchange rates in both academia and policy circles.

Many insist that the JPY depreciation was a unique direct consequence of the aggressive monetary easing adopted by the Bank of Japan (BOJ). This view has gotten strong popularity among academic researchers and market commentators in Japan because the JPY depreciation just started on November 2012, when most market participants expected a radical change in the monetary policy regime of the BOJ due to a strong political pressure from an anticipated new government run by the Liberal Democratic Party (LDP). ${ }^{1}$ Soon after the then LDP Governor Abe won the general election of the Lower House of the Diet on December 2012, the "first arrow" - the bold monetary easing by the BOJ for fighting against chronic deflation in Japan — was announced by new BOJ Governor Kuroda in accordance with Prime Minister Abe under his new economic policy initiative subsequently known as the "Abenomics." ${ }^{2}$ This effect of the first arrow on the JPY depreciation is frequently cited as a successful outcome of the Abenomics.

In this paper, we develop a new view toward the exchange rate implication of the first arrow. We start our discussion relying on an empirical finding by Kano and Morita (2015). Kano and Morita observe that the JPY depreciation after the first arrow has no correlation with the 1 and 2 year short-term interest rate differentials between Japan and the United States, rather it goes in tandem closely with the 5 and 10 year long-term ones. As reported by Kano and Morita, Figure 1 plots (the minus of) the logarithm of the JPY/USD rate along with the nominal government bond interest rate differentials with the 1,2, 3, 5, 7, and 10 year maturities between Japan and the United States since January 2012. Notice that after the first arrow shot off on November 2012 the interest rate differentials of the Japanese Government Bond (JGB) and the U.S. Treasury Bill (USTB) sharply falls over all maturities. The fall in the two-country interest rate differential is more striking with longer maturities of 5, 7, and 10 years than with shorter maturities of 1,2 , and 3 years. The JPY spot rate depreciates against the USD along tightly with such sharp falls in the longer-term interest rate differentials, not in the shorter-term ones.

\footnotetext{
${ }^{1}$ Ueda (2013) emphasizes a significant role of the enormous political pressure placed on the BOJ in the large asset price movements in Japan between November 2012 and May 2013.

${ }^{2}$ Ueda (2013) provides detailed chronology and typology of the BoJ's unconventional monetary policy measures.
} 
To scrutinize more deeply the data association between the JPY/USD rate and the term structure of the two-country interest rate differentials, we conduct simple Fama regression exercises below. Let $S_{t}$ denote the JPY/USD spot rate at period $t, y_{t, n}$ the JGB rate to maturity $n, y_{t, n}^{*}$ the USTB rate to maturity $n$. We then regress the JPY depreciation rate $s_{t+1}-s_{t} \equiv \log S_{t+1}-\log S_{t}$ on the interest rate differential to maturity $n$ :

$$
s_{t+1}-s_{t}=\alpha_{n}+\beta_{n}\left(y_{t, n}-y_{t, n}^{*}\right)+\epsilon_{t, n},
$$

where $\alpha_{n}$ is constant, $\beta_{n}$ is the Fama regression coefficient, and $\epsilon_{t, n}$ is an i.i.d. error term. We also estimate an alternative Fama regression specification with the one-period excess currency return $r x_{t+1} \equiv s_{t+1}-s_{t}+y_{t, 1}^{*}-y_{t, 1}$ as the dependent variable:

$$
r x_{t+1}=\alpha_{n}^{r x}+\beta_{n}^{r x}\left(y_{t, n}-y_{t, n}^{*}\right)+\epsilon_{t, n}^{r x}
$$

where $\alpha_{n}^{r x}$ is constant, $\beta_{n}^{r x}$ is the Fama coefficient, and $\epsilon_{t, n}^{r x}$ is an i.i.d. error term. We investigate the monthly data of the JGB rates, the USTB rates, and the JPY/USD rate spanning the period between January 2008 and August 2015. We estimate the two specifications using (i) the whole sample, (ii) the first subsample before the Abenomics between January 2008 and November 2012, and (iii) the second subsample after the Abenomics between December 2012 and August 2015.

Table 1 reports the OLS point estimates of the Fama coefficients to maturity $n$ and the corresponding standard errors for specification (1) in panel (a) and for specification (2) in panel (b), respectively. The first two raws of panel (a) basically repeat the conventional argument of a randomwalk exchange rate: in the whole sample after the Lehman shock the JPY depreciation rate against the USD has no statistically significant relation with the two-country interest rate differential over all the maturities. The third and fourth raws of the same panel show that this covariance structure between the currency return and the interest rate differential is essentially preserved in the first sub-sample period before the Abenomics, while the slope of the term structure becomes slightly steep over maturities. The term structure of the Fama regression coefficient, however, drastically changes its shape in the second sub-sample period after the onset of the Abenomics. The fifth and sixth raws of panel (a) uncover that (i) the level of the term structure shifts up and (ii) the slope of the term structure becomes steeper. In particular, the point estimate of the Fama coefficient to the 10 year maturity is 2.269 at the conventional statistical significance level. The OLS regression of the alternative specification, which is reported in panel (b), conveys the almost same inferences as drawn in panel (a) except the fact that the negative dependence of the one-period excess currency return on the interest rate differentials to the shorter maturities of 1,2 , and 3 years become statistically significant in the first sub-sample period. ${ }^{3}$

\footnotetext{
${ }^{3}$ Hence, a risk premium explanation for the failure of the uncovered interest parity condition, especially, at the
} 
Figure 2 confirms the structural change in the term structure of the Fama regression coefficients between the two sub-sample periods graphically. The solid blue line represents the estimated term structure of the Fama coefficient in currency return specification (1) in the first sub-sample period, while the dotted blue line the estimated term structure of the Fama coefficient in excess currency return specification (2). The solid and dotted red lines correspond to the second sub-sample period after the Abenomics. Confirm that the term structure of the Fama coefficient is almost flat and there is no strong data association between the currency return and the yield differential before the Abenomics. In the second sub-sample period, the term structure shits up over all maturities and its slope becomes steeper enough to make the correlation between the currency return and the 10 year yield difference a large positive with a statistical significance.

A relevant economic model for the exchange rate effect of the first arrow of the Abenomics, therefore, needs to explain the above structural change in the term structure of the sensitivity of the currency return to the two-country interest rate differential. A successful economic model should have an implication on a relation between a nominal exchange rate and a term structure of two-country nominal bond yield differential. To accomplish this task, we exploit the long-run risk (LRR, hereafter) model recently developed by Bansal and Shaliastovich (2013, hereafter BS). Relying on the Kreps-Porteus, Epstein-Zin recursive preference, the BS model allows persistent components of both the consumption growth rate (real LRR) and the inflation rate (nominal LRR) with the corresponding conditional volatilities. When nominal LRR affects negatively real LRR, the model predicts that the sensitivity of a nominal bond yield to nominal long-run uncertainty (i.e., conditional volatility attached to the nominal LRR) changes the sign over different maturities. In particular the nominal bond yield loading on nominal uncertainty is negative at shorter maturities, while it becomes positive at longer maturities because of a rise in an inflation premium. The covariance between the excess currency return and the yield differential then tends to be less negative and, under plausible parameter values, could be positive at longer maturities. In this case, the depreciation rate is associated positively with the yield differentials with longer maturities. Hence, a currency with a higher long-term yield tends to depreciate.

Importantly, the model predicts the relative size of real and nominal uncertainty matters for the shape and slope of the term structure of the Fama coefficient. Specifically, when nominal uncertainty dominates real uncertainty, the term structure of the Fama coefficient shifts up and becomes steeper. Under a plausible calibration of the model following the BS estimates, we show that the model indeed can replicate fairly well the structural change in the term structure of the Fama coefficient observed in the data when we lower the relative size of real uncertainty to nominal uncertainty. The model, thus, predicts that there should be a change in the component of market uncertainty in the two countries between the two sub-sample periods.

shorter maturities, is also applicable to our sample. 
We, then, ask the following question: where did this change in the component of economic uncertainty occur, in Japan, or the United States or both? We first emphasize the fact that a fall in the long-term interest rate differential between the two countries after the first arrow is mostly originated from a rise in the long-term USTB rates but not from a fall of the corresponding JGB rates. We, thus, confirm that the fall in the long-term interest rate differential is mainly caused by the U.S. side but not from the Japan side. ${ }^{4}$ Using a U.S. 10-year term premium recently estimated by Adrian et al. (2013), we discuss a high possibility that there was a change in the component of market uncertainty in the United States coincidently around the onset of the Abenomics: before 2012 the U.S. market faced both real and nominal uncertainty, while after 2012 nominal uncertainty dominates the U.S. bond market. We, therefore, conjecture that the arrow was shot off from the U.S. side, not the Japan side.

In the next section, we introduce and explain the BS model in details. Section 3 derives the theoretical implication of the model for the term structure of the Fama coefficient and reports the results of our calibration exercise. After discussing our conjecture on the possibility of the U.S. origin of the first arrow, we conclude in Section 4.

\section{A long-run risk approach to the first arrow}

\subsection{The Bansal and Shaliastovich model}

This paper borrows the LRR model of nominal bond yields and currency returns from BS. We construct our hypothesis that the sign flipping of the nominal bond yield loading on nominal uncertainty predicted by the BS model could be a key mechanism to understand the sharp depreciation of JPY against USD after the first arrow. Although the model of this paper is completely identical with that of BS, we nevertheless introduce the model below for detailed explanation.

Consider two countries in each of which the representative agent lives in nfinite periods. Let $m_{t+1}$ and $m_{t+1}^{*}$ denote the logarithms of the home and foreign real stochastic discount factors (SDFs) and $\pi_{t+1}$ and $\pi_{t+1}^{*}$ the home and foreign inflation rates. As discussed by Backus et al. (2001), no arbitrage opportunity under frictionless markets determines the home currency depreciation rate against the foreign currency, $s_{t+1}-s_{t}$, by the difference in the nominal SDF between the foreign and home countries:

$$
s_{t+1}-s_{t}=m_{t+1}^{*}-m_{t+1}-\pi_{t+1}^{*}+\pi_{t+1}
$$

The real SDF in each country is characterized by the representative agent's maximizing the

\footnotetext{
${ }^{4}$ This observation of a negligibly weak response of the long-term JGB rate to the first arrow echoes the findings of Fujiwara et al.(2015) using a Japanese consensus survey data.
} 
Kreps-Porteus, Epstein-Zin recursive preference over consumption

$$
U_{t}=\max _{C_{t}}\left[(1-\delta) C_{t}^{\frac{1-\gamma}{\theta}}+\delta\left(E_{t} U_{t+1}^{1-\gamma}\right)^{\frac{1}{\theta}}\right]^{\frac{\theta}{1-\gamma}}, \quad \theta \equiv \frac{1-\gamma}{1-\frac{1}{\psi}}
$$

subject to the budget constraint

$$
W_{t+1}=\left(W_{t}-C_{t}\right) R_{c, t}
$$

where $\delta \in(0,1)$ is the subjective discount factor, $\gamma \geq 1$ is the risk aversion parameter, $\psi \geq 0$ is the intertemporal elasticity of substitution (IES), and $E_{t}$ is the mathematical conditional expectation operator, $W_{t}$ is the wealth of the household, and $R_{c, t+1}$ is the gross return on the consumption claim (i.e., the asset delivering aggregate consumption as its dividends).

Let $r_{c, t+1}$ denote the rate of return of the consumption claim (i.e., the logarithm of the gross return on the consumption claim). The logarithm of the real SDF implied by the recursive utility is then derived as

$$
m_{t+1}=\theta \log \delta-\frac{\theta}{\psi} \Delta c_{t+1}+(\theta-1) r_{c, t+1},
$$

where $\Delta c_{t+1} \equiv \log C_{t+1}-\log C_{t}$ is the consumption growth rate. ${ }^{5}$ Let $p c_{t}$ describe the wealthconsumption ratio (or, equivalently, the price-dividend ratio of a claim to the aggregate consumption). As discussed by Bansal and Yaron (2004) and Bansal at al. (2007), the rate of return of the consumption claim, $r_{c, t+1}$, is linearly approximated as

$$
r_{c, t+1} \approx \kappa_{0}+\kappa_{1} p c_{t+1}-p c_{t}+\Delta c_{t+1}
$$

where approximating constants $\kappa_{0}$ and $\kappa_{1}$ are given as nonlinear functions of the deterministic steady state level of the wealth-consumtpion ratio, $\bar{p} c$, as

$$
\kappa_{1}=\frac{\exp (\bar{p} c)}{1+\exp (\bar{p} c)}, \quad \text { and } \quad \kappa_{0}=\log (\exp (\bar{p} c)+1)-\kappa_{1} \bar{p} c
$$

where $\kappa_{1} \in\left(\begin{array}{ll}0 & 1\end{array}\right){ }^{6}$

Given real SDF (4), the equilibrium price of any real asset must satisfy the Euler equation

$$
E_{t} \exp \left(m_{t+1}+r_{t+1}\right)=1
$$

where $r_{t+1} \equiv \log \left(R_{t+1}\right)$ is the one-period real rate of return. Similarly, the equilibrium price of any

\footnotetext{
${ }^{5}$ The full derivation of the real SDF (4) is provided by, for example, Bansal and Yaron (2004) and Bansal et al. (2007).

${ }^{6}$ Following Bansal et al.(2007), we numerically solve the steady state wealth-consumption ratio $\bar{p} c$ by a nonlinear root finding program.
} 
nominal asset must satisfy the Euler equation

$$
E_{t} \exp \left(m_{t+1}^{\$}+r_{t+1}^{\$}\right)=1
$$

where $r_{t+1}^{\$} \equiv \log \left(R_{t+1}^{\$}\right)$ is the one-period nominal rate of return and $m_{t+1}^{\$}=m_{t+1}-\pi_{t+1}$ is the nominal SDF.

As specified by BS, we assume that consumption growth rate $\Delta c_{t+1}$ and inflation rate $\pi_{t+1}$ follow exogenous stochastic processes including persistent AR(1) components

$$
\begin{aligned}
\Delta c_{t+1} & =\mu_{c}+x_{c, t}+\sigma_{c} \eta_{c, t+1}, \\
\pi_{t+1} & =\mu_{\pi}+x_{\pi, t}+\sigma_{\pi} \eta_{\pi, t+1}
\end{aligned}
$$

where $\mu_{c}$ and $\mu_{\pi}$ are constants, $\eta_{c, t+1}$ and $\eta_{\pi, t+1}$ are i.i.d. standard normal temporary shocks to the consumption growth and inflation rate, and $\sigma_{c}$ and $\sigma_{\pi}$ are the standard deviations of the consumption growth rate and inflation rate temporary shocks, respectively. Random variables $x_{c, t}$ and $x_{\pi, t}$ are the persistent components of the consumption growth and inflation rate. These real and nominal LRR components are specified as a first-order vector autoregression (VAR) with stochastic volatilities. Let $x_{t}$ denote a $2 \times 1$ random vector including the LRRs as its elements: $x_{t} \equiv\left[x_{c, t} x_{\pi, t}\right]^{\prime}$. Random vector $x_{t}$ follows

$$
x_{t+1}=\prod x_{t}+\Sigma_{t} e_{t+1},
$$

where $\Pi$ is the VAR coefficient matrix specified as

$$
\Pi=\left[\begin{array}{cc}
\rho_{c} & \rho_{c \pi} \\
0 & \rho_{\pi}
\end{array}\right] .
$$

Parameters $\rho_{c}$ and $\rho_{\pi}$, therefore, govern the persistence of the real and nominal LRRs. Parameter $\rho_{c \pi}$ captures the non-neutral effect of expected future inflation on expected future consumption growth. As in BS, we assume the expected future inflation predicts negatively the expected future consumption growth. Hence, $\rho_{c \pi}$ is assumed to be negative.

In eq.(9), $2 \times 1$ random vector $e_{t+1}$ is i.i.d. standard normal shocks to the real and nominal LRRs. Conditional volatility matrix $\Sigma_{t}$ is diagonal and time-varying

$$
\Sigma_{t}=\left[\begin{array}{cc}
\sigma_{x c, t} & 0 \\
0 & \sigma_{x \pi, t}
\end{array}\right],
$$

where $\sigma_{x c, t}$ and $\sigma_{x \pi, t}$ reflect time-varying uncertainty in the real and nominal LRRs. The conditional 
volatilities follow a VAR

$$
\left[\begin{array}{l}
\sigma_{x c, t+1}^{2} \\
\sigma_{x \pi, t+1}^{2}
\end{array}\right]=\left(I_{2}-\Phi\right)\left[\begin{array}{l}
\sigma_{x c}^{2} \\
\sigma_{x \pi}^{2}
\end{array}\right]+\Phi\left[\begin{array}{c}
\sigma_{x c, t}^{2} \\
\sigma_{x \pi, t}^{2}
\end{array}\right]+\Sigma_{w} w_{t+1},
$$

where $\sigma_{x c}^{2}$ and $\sigma_{x \pi}^{2}$ are the unconditional means of the real and nominal volatilities, and $\Phi$ and $\Sigma_{w}$ capture the persistence and the scale of the standard normal volatility shocks $w_{t+1}=\left[\begin{array}{lll}w_{c, t+1} & w_{\pi, t+1}\end{array}\right]^{\prime}$. In particular, $\Phi$ and $\Sigma_{w}$ are orthogonal

$$
\Phi=\left[\begin{array}{cc}
v_{c} & 0 \\
0 & v_{\pi}
\end{array}\right] \quad \text { and } \quad \Sigma_{w}=\left[\begin{array}{cc}
\sigma_{w c} & 0 \\
0 & \sigma_{w \pi}
\end{array}\right] .
$$

Finally, approximating constants $\kappa_{0}$ and $\kappa_{1}$ are endogenously solved as a fixed point of the implicit equation of the deterministic steady state value of the wealth-consumption ratio $\bar{p} c$ :

$$
\overline{p c}=A_{0}(\overline{p c})+A_{s c}(\bar{p} c) \sigma_{x c}^{2}+A_{s \pi}(\overline{p c}) \sigma_{x \pi}^{2}
$$

where $A_{0}(\bar{p} c), A_{s c}(\bar{p} c)$, and $A_{s \pi}(\bar{p} c)$ are implicit functions of $\bar{p} c$.

\subsection{Equilibrium bond yields}

An equilibrium of the model is solved with an undetermined coefficient method. Given state variables $x_{c, t}, x_{\pi, t}, \sigma_{x c, t}^{2}$, and $\sigma_{x \pi, t}^{2}$, we make an educated guess of the equilibrium wealth-consumption ratio

$$
p c_{t}=A_{0}+A_{x c} x_{c, t}+A_{x \pi} x_{\pi, t}+A_{s c} \sigma_{c, t}^{2}+A_{s \pi} \sigma_{\pi, t}^{2} .
$$

To solve unknown coefficients $A_{0}, A_{x c}, A_{x \pi}, A_{s c}$, and $A_{s \pi}$, notice that Euler equation (6) also needs to be satisfied for the one-period return on the consumption claim $r_{c, t+1}$ :

$$
E_{t} \exp \left(m_{t+1}+r_{c, t+1}\right)=1
$$

Substituting real SDF (4), rate of return on the consumption claim (5), and wealth-consumption ratio (14) into the above Euler equation and using the stochastic processes of the exogenous state variables provide five coefficient restrictions for solving the five unknowns in eq.(14). In particular, the sensitivity of the equilibrium wealth-consumption ratio toward the four state variables is 
characterized by the four coefficients

$$
\begin{aligned}
& A_{x c}= \frac{1-\frac{1}{\psi}}{1-\kappa_{1} \rho_{c}}>0, \\
& A_{x \pi}=\kappa_{1} \rho_{c \pi} \frac{1-\frac{1}{\psi}}{\left(1-\kappa_{1} \rho_{c}\right)\left(1-\kappa_{1} \rho_{\pi}\right)}<0, \\
& A_{s c}=\frac{(1-\gamma)\left(1-\frac{1}{\psi}\right)}{2\left(1-\kappa_{1} v_{c}\right)}\left(\frac{\kappa_{1}}{1-\kappa_{1} \rho_{c}}\right)^{2}<0, \\
& A_{s \pi}=\frac{(1-\gamma)\left(1-\frac{1}{\psi}\right)}{2\left(1-\kappa_{1} v_{\pi}\right)}\left\{\frac{\kappa_{1}^{2} \rho_{c \pi}}{\left(1-\kappa_{1} \rho_{c}\right)\left(1-\kappa_{1} \rho_{\pi}\right)}\right\}^{2}<0 .
\end{aligned}
$$

Under the conventional calibration in the LRR literature, the IES is greater than one, i.e., $\psi>1$. In this case, the intertemporal substitution effect dominates the wealth effect. Hence, a higher expected future consumption growth leads to a higher investment to the consumption claim and a higher wealth-consumption ratio as the positive loading $A_{x c}$ implies. The assumed negative nonneutrality of the expected future inflation on the expected consumption growth (i.e., $\rho_{c \pi}<0$ ) results in a negative wealth-consumption loading on the nominal long-run risk (i.e., $A_{x \pi}<0$ ): a higher expected future inflation implies a lower expected future real growth and a lower wealthconsumption ratio. When the degree of the risk aversion is greater than one (i.e., $\gamma>1$ ), higher real as well as nominal volatilities raise the uncertainty on future consumption dividends. Because the equilibrium price of the consumption claim falls, the wealth-consumption ratio responds negatively to the real and nominal volatilities (i.e., $\left.A_{s c}, A_{s \pi}<0\right) .{ }^{7}$

As usual, the real market prices of risks are derived as the forecast error of the real pricing kernel. Substituting equilibrium wealth-consumption ratio (14) into real SDF (4), we can calculate the forecast errors of the real SDF

$m_{t+1}-E_{t} m_{t+1}=-\lambda_{c} \sigma_{c} \eta_{c, t+1}-\lambda_{\pi} \sigma_{\pi} \eta_{\pi, t+1}-\lambda_{x c} \sigma_{x c, t} e_{c, t+1}-\lambda_{x \pi} \sigma_{x \pi, t} e_{\pi, t+1}-\lambda_{s c} \sigma_{w c} w_{c, t+1}-\lambda_{s \pi} \sigma_{w \pi} w_{\pi, t+1}$,

where

$$
\begin{aligned}
& \lambda_{c}=\gamma, \quad \lambda_{\pi}=0, \quad \lambda_{x c}=\left(\gamma-\frac{1}{\psi}\right) \frac{\kappa_{1}}{1-\kappa_{1} \rho_{c}}>0, \quad \lambda_{x \pi}=\left(\gamma-\frac{1}{\psi}\right) \frac{\kappa_{1}^{2} \rho_{c \pi}}{1-\kappa_{1} \rho_{\pi}}<0, \\
& \lambda_{s c}=\left(\gamma-\frac{1}{\psi}\right)(1-\gamma) \frac{\kappa_{1}}{2\left(1-\kappa_{1} v_{c}\right)}\left(\frac{\kappa_{1}}{1-\kappa_{1} \rho_{c}}\right)^{2}<0, \\
& \lambda_{s \pi}=\left(\gamma-\frac{1}{\psi}\right)(1-\gamma) \frac{\kappa_{1}}{2\left(1-\kappa_{1} v_{\pi}\right)}\left(\frac{\kappa_{1}^{2} \rho_{c \pi}}{1-\kappa_{1} \rho_{\pi}}\right)^{2}<0 .
\end{aligned}
$$

\footnotetext{
${ }^{7}$ Constant $A_{0}$ can be solved through the coefficient restriction $\log \delta+\kappa_{0}+\left(1-\frac{1}{\psi}\right) \mu_{c}+A_{0}\left(\kappa_{1}-1\right)+\kappa_{1}\left[A_{s c}(1-\right.$ $\left.\left.v_{c}\right) \sigma_{x c}^{2}+A_{s \pi}\left(1-v_{\pi}\right) \sigma_{x \pi}^{2}\right]+\frac{\theta}{2}\left(1-\frac{1}{\psi}\right)^{2} \sigma_{c}^{2}+\frac{\theta}{2} \kappa_{1}^{2} A_{s c}^{2} \sigma_{w c}^{2}+\frac{\theta}{2} \kappa_{1}^{2} A_{s \pi}^{2} \sigma_{w \pi}^{2}=0$.
} 
The real market price of the temporary consumption growth risk is positive (i.e., $\lambda_{c}>0$ ) due to the positive risk aversion parameter $(\gamma>1)$. Since the instantaneous inflation shock has no impact on the real pricing kernel, its real market price is zero: $\lambda_{\pi}=0$. Under the early resolution of uncertainty (i.e., $\gamma>\frac{1}{\psi}$ ), the real market price of the expected future consumption growth risk is positive (i.,e., $\lambda_{x c}>0$ ), while that of the expected inflation risk is negative (i.e., $\lambda_{x \pi}<0$ ) with the negative non-neutrality of the expected inflation on the consumption growth. The real market prices of the real and nominal volatility risks are both negative: $\lambda_{s c}, \lambda_{s \pi}<0$.

Similarly, the nominal market prices of risks are calculated as the forecast error of the nominal pricing kernel.

$m_{t+1}^{\$}-E_{t} m_{t+1}^{\$}=-\lambda_{c} \sigma_{c} \eta_{c, t+1}-\lambda_{\pi}^{\$} \sigma_{\pi} \eta_{\pi, t+1}-\lambda_{x c} \sigma_{x c, t} e_{c, t+1}-\lambda_{x \pi} \sigma_{x \pi, t} e_{\pi, t+1}-\lambda_{s c} \sigma_{w c} w_{c, t+1}-\lambda_{s \pi} \sigma_{w \pi} w_{\pi, t+1}$,

where the nominal market price of the instantaneous inflation shock is equal to one: $\lambda_{\pi}^{\$}=1$. The other nominal market prices of risks are the same as the corresponding real market prices of risks.

To derive the real bond yields to different maturities, let $p_{t, n}$ denote the logarithm of the price of the real bond to maturity $n$. Similarly to the equilibrium wealth-consumption ratio, we solve equilibrium real bond price $p_{t, n}$ by an undetermined coefficient method. We construct an educated guess of the equilibrium real bond price to maturity $n$ :

$$
p_{t, n}=-B_{0, n}-B_{x c, n} x_{c, t}-B_{x \pi, n} x_{\pi, t}-B_{s c, n} \sigma_{c, t}^{2}-B_{s \pi, n} \sigma_{\pi, t}^{2}
$$

The corresponding real bond yield to maturity $n$, which is denoted by $y_{t, n}$, is simply given as the inverse of the real bond price divided by maturity $n$ :

$$
y_{t, n}=\frac{1}{n}\left(B_{0, n}+B_{x c, n} x_{c, t}+B_{x \pi, n} x_{\pi, t}+B_{s c, n} \sigma_{c, t}^{2}+B_{s \pi, n} \sigma_{\pi, t}^{2}\right) .
$$

To find the equilibrium real bond yield loadings, let $h_{n, t \rightarrow t+1}\left(=p_{t+1, n-1}-p_{t, n}\right)$ denote the corresponding one-period holding return of the real bond to maturity $n$. The real bond price implies the corresponding one-period holding return

$$
\begin{array}{r}
h_{n, t \rightarrow t+1}=\left(B_{0, n}-B_{0, n-1}\right)+\left(B_{x c, n}-\rho_{c} B_{x c, n-1}\right) x_{c, t}+\left(B_{x \pi, n}-\rho_{\pi} B_{x \pi, n-1}-\rho_{c \pi} B_{x c, n-1}\right) x_{\pi, t}, \\
+\left(B_{s c, n}-v_{c} B_{s c, n-1}\right) \sigma_{c, t}^{2}+\left(B_{s \pi, n}-v_{\pi} B_{s \pi, n-1}\right) \sigma_{\pi, t}^{2}-B_{x c, n-1} \sigma_{c, t} e_{c, t+1}-B_{x \pi, n-1} \sigma_{\pi, t} e_{\pi, t+1} \\
-B_{s c, n-1} \sigma_{w c} w_{c, t+1}-B_{s \pi, n-1} \sigma_{w \pi} w_{\pi, t+1}-B_{s c, n-1}\left(1-v_{c}\right) \sigma_{c}^{2}-B_{s \pi, n-1}\left(1-v_{\pi}\right) \sigma_{\pi}^{2} .
\end{array}
$$

The Euler equation implies that under the real pricing kernel, the conditional moment condition

$$
E_{t} \exp \left(m_{t+1}+h_{t \rightarrow t+1, n}\right)=1
$$


must be satisfied. The above moment condition then yields five coefficient restrictions as the equilibrium difference equations of five unknowns $B_{0, n}, B_{x c, n}, B_{x \pi, n}, B_{s c, n}$, and $B_{s \pi, n}$ :

$$
\begin{aligned}
B_{x c, n} & =\rho_{c} B_{x c, n-1}+\frac{1}{\psi} \\
B_{x \pi, n} & =\rho_{\pi} B_{x \pi, n-1}+\rho_{c \pi} B_{x c, n-1} \\
B_{s c, n} & =v_{c} B_{s c, n-1}-\frac{1}{2}(1-\gamma)\left(\gamma-\frac{1}{\psi}\right)\left(\frac{\kappa_{1}}{1-\kappa_{1} \rho_{c}}\right)^{2}-\frac{1}{2}\left(\frac{\frac{1}{\psi}-\gamma}{1-\kappa_{1} \rho_{c}} \kappa_{1}-B_{x c, n-1}\right)^{2}, \\
B_{s \pi, n} & =v_{\pi} B_{s \pi, n-1}-\frac{1}{2}(1-\gamma)\left(\gamma-\frac{1}{\psi}\right)\left[\frac{\kappa_{1}^{2} \rho_{c \pi}}{\left(1-\kappa_{1} \rho_{c}\right)\left(1-\kappa_{1} \rho_{\pi}\right)}\right]^{2} \\
& -\frac{1}{2}\left[\frac{\frac{1}{\psi}-\gamma}{\left(1-\kappa_{1} \rho_{c}\right)\left(1-\kappa_{1} \rho_{\pi}\right)} \kappa_{1}^{2} \rho_{c \pi}-B_{x \pi, n-1}\right]^{2}, \\
B_{0, n} & =B_{0, n-1}+B_{s c, n-1}\left(1-v_{c}\right) \sigma_{x c}^{2}+B_{s \pi, n-1}\left(1-v_{\pi}\right) \sigma_{x \pi}^{2}-\bar{m}-\frac{1}{2}\left(\theta-1-\frac{\theta}{\psi}\right)^{2} \sigma_{c}^{2} \\
& -\frac{1}{2}\left[(\theta-1) \kappa_{1} A_{s c}-B_{s c, n-1}\right]^{2} \sigma_{w c}^{2}-\frac{1}{2}\left[(\theta-1) \kappa_{1} A_{s \pi}-B_{s \pi, n-1}\right]^{2} \sigma_{w \pi}^{2},
\end{aligned}
$$

where $\bar{m}$ is the unconditional mean of the real pricing kernel. The restriction that the real bond price to the zero maturity should be zero (i.e., $p_{t, 0}=0$ ) imposes the zero restrictions on the initial real bond yield loadings $B_{0,0}=B_{x c, 0}=B_{x \pi, 0}=B_{s c, 0}=B_{s \pi, 0}=0$. Starting with the initial conditions, recursion of the equilibrium difference equations solves the equilibrium real bond yields to any maturity $n$.

The agent holds the real bond for hedging an expected future consumption risk. A lower expected consumption growth increases the demand for the real bond and, hence, raises the real bond price and falls the real bond yields to all maturities: $B_{x c, n}>0$. With the negative nonneutrality of expected future inflation to expected future consumption growth (i.e., $\rho_{c \pi}<0$ ), a higher expected inflation deteriorates the agent's perspective of the future consumption growth, raises the real bond price, and falls the real bond yield: $B_{x \pi, n}<0$. Careful investigation uncovers that under the early resolution of uncertainty, the real bond yield loading on the real and nominal volatilities are negative: $B_{s c, n}<0$ and $B_{s \pi, n}<0$. Because a higher real volatility implies that the future consumption dividend is more uncertain, the agent desires to invest more into the real bond. Through this "flight to quality" (hereafter FTQ) effect, the real bond price rises and the real bond yield falls. The FTQ effect also produces the negative sensitivity of the real bond yield to the nominal volatility: the higher the inflation volatility, the higher the real volatility under the negative non-neutrality of expected inflation on future consumption growth. Thus, the real bond price rises and the real bond yield falls in response to a rise in the nominal volatility.

The exactly same steps are applicable to derive the equilibrium nominal bond yield to maturity 
$n, y_{t, n}^{\$}:$

$$
y_{t, n}^{\$}=\frac{1}{n}\left(B_{0, n}^{\$}+B_{x c, n}^{\$} x_{c, t}+B_{x \pi, n}^{\$} x_{\pi, t}+B_{s c, n}^{\$} \sigma_{c, t}^{2}+B_{s \pi, n}^{\$} \sigma_{\pi, t}^{2}\right) .
$$

The nominal Euler equation then provides five coefficient restrictions as the equilibrium difference equations of five unknowns $B_{0, n}^{\$}, B_{x c, n}^{\$}, B_{x \pi, n}^{\$}, B_{s c, n}^{\$}$, and $B_{s \pi, n}^{\$}$ :

$$
\begin{aligned}
B_{x c, n}^{\$} & =\rho_{c} B_{x c, n-1}^{\$}+\frac{1}{\psi}, \\
B_{x \pi, n}^{\$} & =\rho_{\pi} B_{x \pi, n-1}^{\$}+\rho_{c \pi} B_{x c, n-1}^{\$}+1 \\
B_{s c, n}^{\$} & =v_{c} B_{s c, n-1}^{\$}-\frac{1}{2}(1-\gamma)\left(\gamma-\frac{1}{\psi}\right)\left(\frac{\kappa_{1}}{1-\kappa_{1} \rho_{c}}\right)^{2}-\frac{1}{2}\left(\frac{\frac{1}{\psi}-\gamma}{1-\kappa_{1} \rho_{c}} \kappa_{1}-B_{x c, n-1}^{\$}\right)^{2}, \\
B_{s \pi, n}^{\$} & =v_{\pi} B_{s \pi, n-1}^{\$}-\frac{1}{2}(1-\gamma)\left(\gamma-\frac{1}{\psi}\right)\left[\frac{\kappa_{1}^{2} \rho_{c \pi}}{\left(1-\kappa_{1} \rho_{c}\right)\left(1-\kappa_{1} \rho_{\pi}\right)}\right]^{2} \\
& -\frac{1}{2}\left[\frac{\frac{1}{\psi}-\gamma}{\left(1-\kappa_{1} \rho_{c}\right)\left(1-\kappa_{1} \rho_{\pi}\right)} \kappa_{1}^{2} \rho_{c \pi}-B_{x \pi, n-1}^{\$}\right]^{2}, \\
B_{0, n}^{\$} & =B_{0, n-1}^{\$}+B_{s c, n-1}^{\$}\left(1-v_{c}\right) \sigma_{x c}^{2}+B_{s \pi, n-1}^{\$}\left(1-v_{\pi}\right) \sigma_{x \pi}^{2}-\bar{m}+\mu_{\pi}-\frac{1}{2}\left(\theta-1-\frac{\theta}{\psi}\right)^{2} \sigma_{c}^{2}-\frac{1}{2} \sigma_{\pi}^{2} \\
& -\frac{1}{2}\left[(\theta-1) \kappa_{1} A_{s c}-B_{s c, n-1}^{\$}\right]^{2} \sigma_{w c}^{2}-\frac{1}{2}\left[(\theta-1) \kappa_{1} A_{s \pi}-B_{s \pi, n-1}^{\$}\right]^{2} \sigma_{w \pi}^{2}
\end{aligned}
$$

The restriction that the nominal bond price to the zero maturity should be zero (i.e., $p_{t, 0}^{\$}=0$ ) imposes the zero restrictions on the initial nominal bond yield loadings $B_{0,0}^{\$}=B_{x c, 0}^{\$}=B_{x \pi, 0}^{\$}=$ $B_{s c, 0}^{\$}=B_{s \pi, 0}^{\$}=0$. Starting with the initial conditions, recursion of the equilibrium difference equations solves the equilibrium nominal bond yields to any maturity $n$.

The hedging purpose for the expected future consumption risk also explains the positive nominal bond yield loading: $B_{x c, n}^{\$}>0$. Because the expected future inflation directly affects the nominal pricing kernel negatively, the nominal bond yield loading on an inflation expectation is positive: $B_{x \pi, n}^{\$}>0$. Moreover the real volatility creates a FTQ effect and falls the nominal bond yields: $B_{s c, n}^{\$}<0$.

The most outstanding characteristic of the BS model is that the sign of the nominal bond yield loading on the nominal volatility changes over maturities. In particular, $B_{s \pi, n}$ is negative at shorter maturities, while it becomes positive at longer maturities. To understand the reason behind this sign flipping of the nominal bond yield sensitivity to the inflation volatility, notice that the nominal bond yield to maturity $n$ is

$$
y_{t, n}^{\$}=y_{t, n}+\frac{1}{n} E_{t} \sum_{i=1}^{n} \pi_{t+i}-\frac{1}{2 n} V_{t}\left(\sum_{i=1}^{n} \pi_{t+i}\right)+\frac{1}{n} \operatorname{Cov}_{t}\left(\sum_{i=1}^{n} m_{t+i}, \sum_{i=1}^{n} \pi_{t+i}\right) .
$$


where $V_{t}$ and $\operatorname{Cov}_{t}$ are the mathematical conditional variance and covariance operators. Our discussion has already suggested that the nominal volatility lowers the real bond yield $y_{t, n}$ through a FTQ effect (i.e., $B_{s \pi, n}<0$ ). The third term of the RHS reflects a Jensen's inequality adjustment and its sensitivity to the nominal volatility decreases in maturity $n .{ }^{8}$ The fourth term captures an inflation premium, which is given as the covariance between the multi-period real pricing kernel and inflation. It could be shown then that the inflation premium term becomes larger at longer maturities and gradually dominates both the FTQ effect and the Jensen's inequality adjustment as the maturity becomes longer.

\section{Revisiting the first arrow hitting the currency target}

Why did the depreciation rate of the JPY against the USD drastically increase its sensitivity to the two-country yield differentials at longer maturities right after the introduction of the first arrow of the Abenomics? The model resolves this question by revealing important roles of real and nominal LRR uncertainty in the term structure of the Fama coefficient. We now characterize the equilibrium term structure of the Fama regression coefficient.

\subsection{Term structure of the Fama coefficient}

We assume throughout the rest of the paper that the two countries share the identical structural parameters. For any random variable for the home and foreign countries $v_{t}$ and $v_{t}^{*}$, let $\tilde{v}_{t}$ denote the corresponding cross-country differential: $\tilde{v}_{t} \equiv v_{t}-v_{t}^{*}$. Notice that the equilibrium depreciation rate (3) then can be rewritten as

$$
\begin{aligned}
s_{t+1}-s_{t} & =E_{t}\left(m_{t+1}^{*}-\pi_{t+1}^{*}\right)-E_{t}\left(m_{t+1}-\pi_{t+1}\right)+\left(m_{t+1}^{*}-E_{t} m_{t+1}^{*}\right)-\left(\pi_{t+1}^{*}-E_{t} \pi_{t+1}^{*}\right) \\
& -\left(m_{t+1}-E_{t} m_{t+1}\right)+\left(\pi_{t+1}-E_{t} \pi_{t+1}\right), \\
& =\tilde{y}_{t, 1}+\frac{1}{2} \lambda_{s c}^{2} \tilde{\sigma}_{x c, t}^{2}+\frac{1}{2} \lambda_{s \pi}^{2} \tilde{\sigma}_{x \pi, t}^{2}+\lambda_{c} \sigma_{c} \tilde{\eta}_{c, t+1}+\lambda_{\pi}^{\$} \sigma_{\pi} \tilde{\eta}_{\pi, t+1}+\lambda_{x c} \sigma_{x c, t} \tilde{e}_{c, t+1}+\lambda_{x \pi} \sigma_{x \pi, t} \tilde{e}_{\pi, t+1} \\
& +\lambda_{s c} \sigma_{w c} \tilde{w}_{c, t+1}+\lambda_{s \pi} \sigma_{w \pi} \tilde{w}_{\pi, t+1} .
\end{aligned}
$$

Using nominal bond yield equation (15), we can derive the unconditional covariance between the depreciation rate and the cross-country yield differential to maturity $n$ :

$$
\operatorname{Cov}\left(s_{t+1}-s_{t}, \quad \tilde{y}_{t, n}^{\$}\right)=\operatorname{Cov}\left(\tilde{y}_{1, t}^{\$}, \quad \tilde{y}_{t, n}^{\$}\right)+\operatorname{Cov}\left(r x_{t+1}, \tilde{y}_{t, n}^{\$}\right)
$$

\footnotetext{
${ }^{8}$ Notice that the nominal bond yield is an log inverse of the expected multi-period nominal SDF. Hence an increase in the variance of the multi-period nominal SDF through a higher variance of future inflation lowers the nominal bond yield through the $\log$ transformation.
} 
where

$$
\begin{aligned}
\operatorname{Cov}\left(\tilde{y}_{1, t}^{\$}, \tilde{y}_{t, n}^{\$}\right) & =\frac{1}{n} B_{x c, 1}^{\$} B_{x c, n}^{\$} V\left(\tilde{x}_{c, t}\right)+\frac{1}{n} B_{x \pi, 1}^{\$} B_{x \pi, n}^{\$} V\left(\tilde{x}_{\pi, t}\right)+\frac{1}{n} B_{s c, 1}^{\$} B_{s c, n}^{\$} V\left(\tilde{\sigma}_{x c, t}^{2}\right) \\
& +\frac{1}{n} B_{s \pi, 1}^{\$} B_{s \pi, n}^{\$} V\left(\tilde{\sigma}_{x \pi, t}^{2}\right), \\
\operatorname{Cov}\left(r x_{t+1}, \tilde{y}_{t, n}^{\$}\right) & =\frac{1}{2 n} \lambda_{s c}^{2} B_{s c, n}^{\$} V\left(\tilde{\sigma}_{x c, t}^{2}\right)+\frac{1}{2 n} \lambda_{s \pi}^{2} B_{s \pi, n}^{\$} V\left(\tilde{\sigma}_{x \pi, t}^{2}\right) .
\end{aligned}
$$

Eq.(17) implies that the unconditional covariance between the depreciation rate and the yield differential to maturity $n$ can be decomposed into two unconditional covariance terms, (i) that between the yield differential to the one-period maturity and that to maturity $n$ (eq.18) and (ii) that between the excess currency return and the yield differential to maturity $n$ (eq.19). Observe that except a longer maturity the former covariance is always positive. The latter covariance, however, is negative at least to short maturities because the first and second terms of the RHS of eq.(19) are negative over short maturities. This negative association between the excess currency return and the yield differential to short maturities is indeed the fundamental source of the Fama puzzle: a currency with a higher short-term yield tends to appreciate.

The crucial implication of BS model is that the Fama puzzle becomes less severe at longer maturities. To see this, remember that the nominal bond yield loading changes its sign from negative to positive at longer maturities. The covariance between the excess currency return and the yield differential then tends to be less negative and, under plausible parameter values, could be positive at longer maturities. In this case, the depreciation rate is associated positively with the yield differential with longer maturities. Therefore, a currency with a higher long-term yield tends to depreciate.

\subsection{Benchmark calibration}

To see whether the model indeed generates an upward-sloping term structure of the Fama regression coefficients, we calibrate the model simply following BS. Table 1 summarizes our benchmark calibration of the model. All the parameter values except the standard deviations of the real and nominal volatility shocks, $\sigma_{w c}$ and $\sigma_{w \pi}$, stem from the results of the BS estimation of the model with quarterly data of the United States and the United Kingdom spanning the period between 1969 and 2010. In particular, $\tau_{x c} \equiv \operatorname{Cov}\left(e_{c, t+1}, e_{c, t+1}^{*}\right), \tau_{x \pi} \equiv \operatorname{Cov}\left(e_{\pi, t+1}, e_{\pi, t+1}^{*}\right), \tau_{s c} \equiv \operatorname{Cov}\left(w_{c, t+1}, w_{c, t+1}^{*}\right)$, and $\tau_{s \pi} \equiv \operatorname{Cov}\left(w_{\pi, t+1}, w_{\pi, t+1}^{*}\right)$ are the unconditional instantaneous correlation coefficients in the real and nominal LRR shocks and the real and nominal volatility shocks between the two countries. ${ }^{9}$ We also follow the results of BS's minimum distance estimation to calibrate these correlation

\footnotetext{
${ }^{9}$ Under the assumption of the identical structural parameters in the two countries, we can calculate variance terms $V\left(\tilde{x}_{c, t}\right)=\frac{2 \sigma_{x c}^{2}\left(1-\tau_{x c}\right)}{1-\rho_{c}^{2}}, V\left(\tilde{x}_{\pi, t}\right)=\frac{2 \sigma_{x \pi}^{2}\left(1-\tau_{x \pi}\right)}{1-\rho_{\pi}^{2}}, V\left(\tilde{\sigma}_{x c, t}^{2}\right)=\frac{2 \sigma_{w c}^{2}\left(1-\tau_{s c}\right)}{1-v_{c}^{2}}$, and $V\left(\tilde{\sigma}_{x \pi, t}^{2}\right)=\frac{2 \sigma_{w \pi}^{2}\left(1-\tau_{s \pi}\right)}{1-v_{\pi}^{2}}$.
} 
coefficients. We calibrate $\sigma_{w c}$ and $\sigma_{w \pi}$ to higher values of $7.95 \mathrm{e}-07$ and $2.51 \mathrm{e}-07$ than the corresponding BS estimates of $1.85 \mathrm{e}-07$ and $1.81 \mathrm{e}-07$, respectively. This calibration reflects our prior belief that during the GFC after the Lehman shock in 2008, both real and nominal uncertainty greatly increased relative to that during the Great Moderation period.

Figure 3 indeed displays the term structure of the Fama regression coefficients at maturities $1,2,3,5,7$, and 10 years implied by the benchmark specification of the model. The solid blue line depicts the sizes of the population regression coefficients of the depreciation rate on the twocountry yield differential to maturity $n$, i.e., $\operatorname{Cov}\left(s_{t+1}-s_{t}, \tilde{y}_{t, n}^{\$}\right) / V\left(\tilde{y}_{t, n}^{\$}\right)$, while the dotted blue line the sizes of the population regression coefficients of the one-period excess currency return on the two-country yield differential to maturity $n$, i.e., $\operatorname{Cov}\left(r x_{t+1}^{\$}, \tilde{y}_{t, n}^{\$}\right) / V\left(\tilde{y}_{t, n}^{\$}\right)$. Observe that the benchmark model replicates the actual data shape of the term structure of the Fama coefficient before the first arrow fairly well: as reported in Figure 2, the Fama coefficient is negative at shorter maturities up to 3 years but turns to be positive at longer maturities after 5 years. The excess currency return regression coefficients clearly uncover that this upward-sloping term structure of the Fama coefficient reflects the key theoretical property of the model: the negative correlation between the excess currency return and the yield differential generated by the real and nominal conditional volatilities, as in eq.(19), gradually weakens because nominal uncertainty increases the inflation premium effect enough to dominate the FTQ effect as well as the Jensen's inequality effect when the yield maturity becomes longer.

\subsection{Roles of real and nominal uncertainty}

Why did the term structure of the Fama coefficient shift up and become steeper after the first arrow? We now draw our theoretical inference from the model: real uncertainty in expected future consumption growth was mitigated around the first arrow and nominal uncertainty in expected future inflation rate and/or future monetary policy path dominated domestic and international financial markets after the first arrow.

To see this theoretical prediction, recall that a fall in real uncertainty mutes the FTQ effect (i.e., $B_{s c, n}^{\$}<0$ ) and leads to a higher nominal bond yield. As shown by eq.(19), the covariance between the excess currency return and the yield differential then rises over all maturities. Nominal uncertainty then dominates this covariance. Besides, as shown by BS, the slope of the nominal bond yield loading on the nominal volatility is positive and quite steep over maturity $n .{ }^{10}$ This means that given a fall in real uncertainty the positive association between the excess currency return and the yield differential enlarges especially at longer maturities. The term structure of the Fama regression coefficient, hence, becomes steeper.

\footnotetext{
${ }^{10}$ See their Figure 4.
} 
To check the validity of the theoretical prediction, we calculate the term structure of the Fama regression coefficient with an alternative calibration of the model. In the new calibration, we change only the size of real uncertainty specifying that the standard deviation of the real volatility $\sigma_{w c}$ falls from $7.95 \mathrm{e}-07$ to $1.85 \mathrm{e}-07 .{ }^{11}$ We call the new calibrated model the nominal uncertainty model. Figure 3 also plots the term structure of the Fama coefficient as the solid red line and the excess currency return regression coefficient as the dotted red line, respectively predicted by the nominal uncertainty model. For comparison, we also plot the results from the benchmark model as the solid and dotted blue lines. The figure clearly reveals three facts. First, comparing with the term structure of the Fama coefficient under the benchmark model, the nominal uncertainty model generates a much higher and steeper term of structure. Second, although the nominal uncertainty model tends to over-evaluate the Fama coefficients at 7 and 10 year maturities, it tracks the actual data shape of the term structure of the Fama coefficient fairly well. ${ }^{12}$ Finally, as the third fact, the most part of the upward-sloping term structure of the Fama coefficient reflects the upward-sloping term structure of the covariance between the excess currency return and the yield differential as observed in the data.

We therefore conclude that the BS model can capture the most data aspects of the term structure of the Fama regression coefficient before and after the first arrow of the Abenomics. In particular, the lens of the BS model provides us with a novel picture of the currency outcome of the Abenomics: the main cause of the sharp depreciation of the JPY against the USD and its tight linkage with longer-term yield differentials between the two countries after the first arrow would be a mitigation of real uncertainty prevailed since the Lehman shock and a resulting dominance of nominal uncertainty in the bond markets of the two countries. But which country matters more significantly?

\subsection{Discussion: where did the first arrow shoot off?}

Figure 4 plots that the 10-year JGB rate as the blue line, the 10-year USTB rate as the red line, and the 10-year interest rate differential between Japan and the United States as the green line in our whole sample period. The shaded areas display the periods when the Fed conducted the three quantitative easing (QE) policies (i.e., QE1, QE2, and QE3). The figure reveals four important facts. First, the long-term JGB rate sticks around $1 \%$ along a downward trend line and has no

\footnotetext{
${ }^{11}$ This calibration of $\sigma_{w c}$ comes from the corresponding estimate of BS. BS estimate $\sigma_{w c}$ using quarterly data of the United States spanning the period between 1969 and 2010. Hence, their calibration represents the average size of the real uncertainty in the United States mostly before the GFC. Hence our exercise reflects the standard conjecture that during the GFC real uncertainty sharply increased in the United States.

${ }^{12}$ Koijen et al. (2010) also point out that a version of the BS model tends to generate counterfactually large nominal bond yields at longer maturities. Because we calibrate the model based on the estimates of BS with U.S.and U.K. quarterly data, it might be possible to resolve this over-valuation of long-term nominal bond yields if we fit the model to Japanese data. We will leave this empirical task as a future research agenda.
} 
big action around the onset of the Abenomics. We can observe a tiny dip of the JGB rate between January and April 2013 but the rate gets back to the trend line very quickly. Second, contrary to the JGB rate, the long-term USTB rate has a lot of actions. The USTB rate sharply falls from 4 $\%$ to $2 \%$ before 2013 and sharply increases above $3 \%$ after May 2013 due to the "taper tantrum." Third, the USTB rate tends to increase during each QE period, although QE1 generates a sharp fall in the long-term USTB rate at the beginning of the program. Fourth, the movement of the yield differential between Japan and the United States is mainly dominated by the action in the USTB rate not the JGB rate. In particular, we can confirm that the fall in the yield differential after the end of 2012 is dominated mostly by the large increase in the USTB rate, not by the small fall in the JGB rate. These facts throw serious doubt on the popular claim across the policy debates in Japan that the first arrow, which hit the currency target of the Japanese yen, shot off from the Japan side. The data of the long-term yields of the two countries clearly uncover that rather the arrow shot off from the U.S. side.

A natural question is then the following: what factors explain such active movements of the long-term USTB rate in our sample? To figure out this question, it is quite informative to decompose the USTB rate fluctuations into the components of the risk-neutral rate and the term premium. Adrian et al. (2013) recently estimate the USTB term premium by estimating their affine term structure model. Figure 5 plots their estimates of the 10-year treasury term premium and the corresponding risk neutral rate. ${ }^{13}$ The shaded areas again exhibit the three U.S. QE periods. According to their estimates, it is useful to split the whole sample into the first and second parts at the mid 2012 with respect to the term premium. Each part is well characterized by high term premiums. More specifically, the term premium keeps being high after the onset of the Lehman shock, then sharply falls from above $2 \%$ on June 2011 to below $0 \%$ on May 2012. After August 2012 the term premium starts increasing and peaks out on December 2013.

Importantly, we observe that each QE tends to raise the term premium during the the program. ${ }^{14}$ This rise in the term premium in fact is the main cause of the tendency that each QE creates an upward pressure on the long-term USTB rate. This observation leads to our conjecture: these large scale bond purchasing programs are recognized to a great degree by market participants as uncertainty about the U.S. monetary policy through enlarging market disagreements about long-run perspective on inflation rates.

On the one hand, the main risk factor prevailed the U.S. market in the first sub-sample

\footnotetext{
${ }^{13}$ Thanks to the authors, the daily and monthly estimates are downloadable at the Federal Reserve Bank of New York website with URL http://www.newyorkfed.org/research/data_indicators/term_premia.html.

${ }^{14}$ Abrahams et al. (2015) report empirical evidence that the large scale asset purchasing programs of the Fed decline the 2 and 10 year real and nominal bond yields on several days right after the policy announcements, especially in the case of QE1. We completely agree with their inference that the QE policies in total has a short-run compressing effect on the U.S. medium- and long-term bond yields.
} 
period is both real and nominal uncertainty. As observed by Abrahams et al. (2015), a variety of indicators for real economic activity including the unemployment rate and consumer confidence highly comove with the term premium inferring a sharp rise in real uncertainty after the Lehman shock and the subsequent GFC. As suggested by Figure 5, the policy response of the Fed with unconventional monetary policies including QEs is likely to contribute to developing high nominal uncertainty. As predicted by the BS model, this co-existence of real and nominal uncertainty is the crucial characteristic to figure out the low and flat term structure of the Fama regression coefficient estimated in the first sub-sample period. On the other hand, the main risk factor behind mounting up the term premium in the second part of the sample is evident: uncertainty about the future path of Fed's unconventional monetary policy due to tapering QE3. As mentioned by Abrahams et al. (2015) and Bernanke (2015), the sharp rise in the term premium obviously reflects the taper tantrum episode of the early summer of 2013. Nominal uncertainty with respect to the long-run perspective of Fed's monetary policy and inflation rate prevailed in the U.S. long-term bond market during this period of time. The LRR model indeed consistently understands that the dominance of U.S. nominal uncertainty generates both the increase in U.S. long-term yield and the JPY depreciation.

\section{Conclusion}

In sum, the paper draws an inference that the arrow comes from the U.S. side not the Japan side. The two-country data of the term structure of the nominal government bond yield shows no clear evidence for a significant role that the first arrow from the BOJ plays in the drastic depreciation the JPY against the USD after the onset of the Abenomics. The conjecture of this paper casts serious doubt on the popular notion of the successful outcome of the Abenomics for the currency target.

Our inference, of course, is subject to several important reservations. First, we adopt the estimate of the LRR model by BS with quarterly data of the United Kingdom and the United States. More careful investigation requires us to estimate the BS model using Japanese data. Second, to derive the theoretical implication for the upward-sloping nominal bond yield over maturities the BS model depends crucially on the negative non-neutrality of the expected future inflation toward expected future consumption growth (i.e., $\rho_{c \pi}<0$ ). It is difficult to justify this maintained assumption theoretically with a solid micro-foundation as well as empirically with data of advanced countries. Even with these reservations we hope that the exercise of this paper will deepen our understanding of the fundamental mechanism behind the recent depreciation of the JPY against the U.S. dollar from the novel long-run risk perspective. 


\section{References}

Abrahams, M., Adrian, T., Crump, R.K., Moench, E., 2015, Decomposing real and nominal yield curves, Federal Reserve Bank of New York Staff Report No.570.

Adrian, T. Crump, R.K., Moench, E., 2013, Pricing the term structure with linear regressions, Journal of Finance Economics 110, 110 - 138.

Backus, D.K., Foresi, S., Telmer, C. I., 2001, Affine term structure models and the forward premium anomaly, Journal of Finance 56, 279 - 304.

Bansal, R., Kiku, D., Yaron, A., 2007, Risks for the long run: estimation and inference, Duke University and University of Pennsylvania.

Bansal, R., Shaliastovich, I., 2013, A long-run risks explanation of predictability puzzles in bond and currency markets, Review of Financial Studies 26, 1 - 33.

Bansal, R., Yaron, A., 2004, Risks for the long run: a potential resolution of asset pricing puzzles, Journal of Finance 59, 1481 - 1509.

Bernanke, B. S., 2015, Why are interest rates so low, part 4: term premiums, Ben Bernanke's Blog April 13.

Fujiwara, I., Nakazono, Y., Ueda, K., 2015, Policy regime change against chronic deflation? Policy option under a long-term liquidity trap, Journal of the Japanese and International Economies $37,59-81$.

Kano, T., Mortia, H., 2015, An equilibrium foundation of the Soros chart, Journal of the Japanese and International Economies 37, $21-42$.

Koijen, R.S.J., Lustig, H., Nieuwerburgh, S.V., Verdelhan, A., 2010, Long run risk, the wealthconsumption ratio, and temporal pricing of risk, American Economic Review 100(2), 552 - 556.

Ueda, K., 2013, Response of asset prices to monetary policy under Abenomics, Asian Economic Policy Review 8, 252 - 269. 


\section{Table 1: Estimated Term Structure of Fama Coefficients}

\begin{tabular}{llcccccc}
\hline \hline \multirow{2}{*}{ Sample Period } & & \multicolumn{7}{c}{ Yields to Maturity } \\
& \multicolumn{7}{c}{ (a) $s_{t+1}-s_{t}=\alpha_{n}+\beta_{n}\left(y_{t, n}-y_{t, n}^{*}\right)+\epsilon_{t, n}$} \\
$2008 / 1-2015 / 8$ & $\hat{\beta}_{n}$ & 0.304 & 0.158 & 0.068 & 0.361 & 0.496 & 0.523 \\
& s.e. & 0.684 & 0.675 & 0.614 & 0.534 & 0.503 & 0.539 \\
$2008 / 1-2012 / 11$ & $\hat{\beta}_{n}$ & -0.305 & -0.427 & -0.342 & 0.120 & 0.269 & 0.343 \\
& s.e. & 0.693 & 0.694 & 0.636 & 0.559 & 0.530 & 0.563 \\
& & & & & & \\
$2012 / 12-2015 / 8$ & $\hat{\beta}_{n}$ & 1.092 & 0.873 & 1.296 & 1.708 & 1.765 & $2.269^{*}$ \\
& s.e. & 3.792 & 2.169 & 1.543 & 1.144 & 1.118 & 1.243 \\
& & $(b) r x_{t+1}=\alpha_{n}^{r x}+\beta_{n}^{r x}\left(y_{t, n}-y_{t, n}^{*}\right)+\epsilon_{t, n}$ & & \\
$2008 / 1-2015 / 8$ & $\hat{\beta}_{n}^{r x}$ & -0.769 & -0.789 & -0.634 & -0.088 & 0.138 & 0.150 \\
& s.e. & 0.666 & 0.657 & 0.598 & 0.525 & 0.495 & 0.531 \\
$2008 / 1-2012 / 11$ & $\hat{\beta}_{n}^{r x}$ & $-1.374^{* *}$ & $-1.392^{* *}$ & $-1.090^{*}$ & -0.395 & -0.153 & -0.121 \\
& s.e. & 0.665 & 0.666 & 0.616 & 0.553 & 0.527 & 0.561 \\
$2012 / 12-2015 / 8$ & $\hat{\beta}_{n}^{r x}$ & 0.258 & 0.474 & 1.093 & 1.638 & 1.733 & $2.320^{*}$ \\
& s.e. & 4.217 & 2.378 & 1.630 & 1.279 & 1.163 & 1.297 \\
\hline
\end{tabular}

Note 1. $r x_{t+1} \equiv s_{t+1}-s_{t}+y_{t, 1}^{*}-y_{t, 1}$ is the one-period excess currency return.

Note 2. $* *$ and $*$ stands for the 5 and $10 \%$ levels of statistical significance. 


\section{Table 2: Baseline Calibration of Bansal and Shaliastovich Model}

\begin{tabular}{|c|c|c|}
\hline & Parameters & Values \\
\hline \multicolumn{3}{|c|}{ Preference } \\
\hline$\delta$ & Subjective Discount Factor & 0.994 \\
\hline$\gamma$ & Risk Aversion & 12.00 \\
\hline$\psi$ & Intertemporal Substitution Elasticity & 1.810 \\
\hline \multicolumn{3}{|c|}{ Consumption Growth } \\
\hline$\mu_{c}$ & Mean Consumption Growth & $4.9 \mathrm{e}-03$ \\
\hline$\sigma_{c}$ & Temporary Consumption Growth Shock Std. & $4.6 \mathrm{e}-03$ \\
\hline$\rho_{c}$ & Persistent Consumption Growth AR(1) Coef. & 0.810 \\
\hline$\rho_{c \pi}$ & Non-neutrality Coef. of Expected Inflation & -0.047 \\
\hline$\sigma_{x c}$ & Persistent Consumption Growth Shock Std. & $1.09 \mathrm{e}-03$ \\
\hline \multicolumn{3}{|c|}{ Inflation Rate } \\
\hline$\mu_{\pi}$ & Mean Inflation Rate & $9.0 \mathrm{e}-03$ \\
\hline$\sigma_{\pi}$ & Temporary Inflation Shock Std. & $5.5 \mathrm{e}-03$ \\
\hline$\rho_{\pi}$ & Persistent Inflation Rate AR(1) Coef. & 0.988 \\
\hline$\sigma_{x \pi}$ & Persistent Inflation Shock Std. & $1.11 \mathrm{e}-03$ \\
\hline \multicolumn{3}{|c|}{ Conditional Volatilities } \\
\hline$v_{c}$ & Consumption Growth Volatility AR(1) Coef. & 0.994 \\
\hline$v_{\pi}$ & Inflation Rate Volatility AR(1) Coef. & 0.979 \\
\hline$\sigma_{w c}$ & Consumption Growth Volatility Shock Std. & $7.95 \mathrm{e}-07$ \\
\hline$\sigma_{w \pi}$ & Inflation Rate Volatility Shock Std. & $2.51 \mathrm{e}-07$ \\
\hline \multicolumn{3}{|c|}{ Two-country Shock Correlations } \\
\hline$\tau_{x c}$ & Corr Coef. in Persistent Consumption Growth Shock & 0.820 \\
\hline$\tau_{x \pi}$ & Corr Coef. in Temporary Inflation Rate Shock & 0.990 \\
\hline$\tau_{s c}$ & Corr Coef. in Consumption Growth Volatility Shock & 0.940 \\
\hline$\tau_{s \pi}$ & Corr Coef. in Inflation Rate Volatility Shock & 0.960 \\
\hline
\end{tabular}

Note. All the parameters except $\sigma_{w c}$ and $\sigma_{w \pi}$ are calibrated from the corresponding estimates of Bansal and Shaliastovich (2013). 


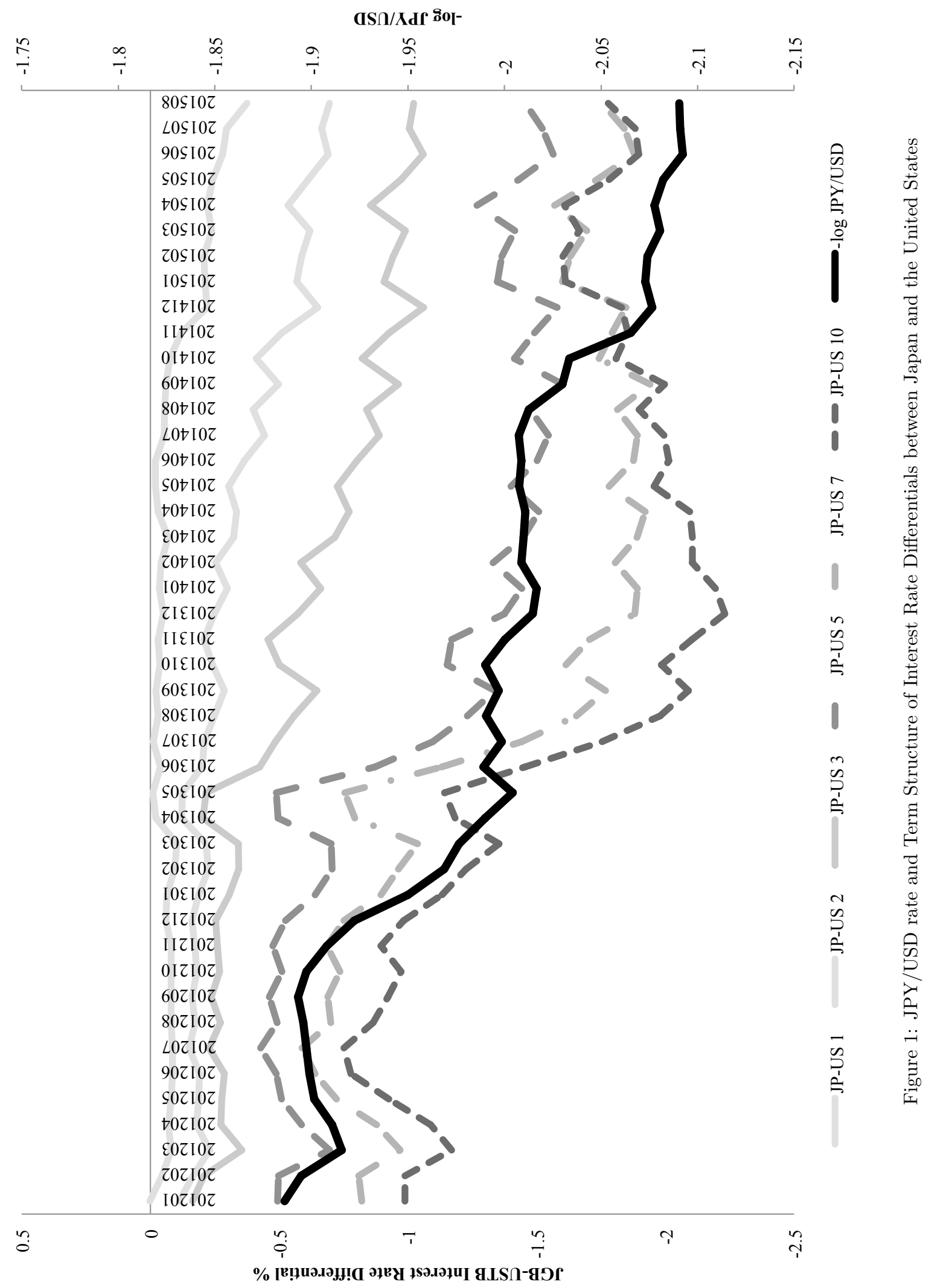




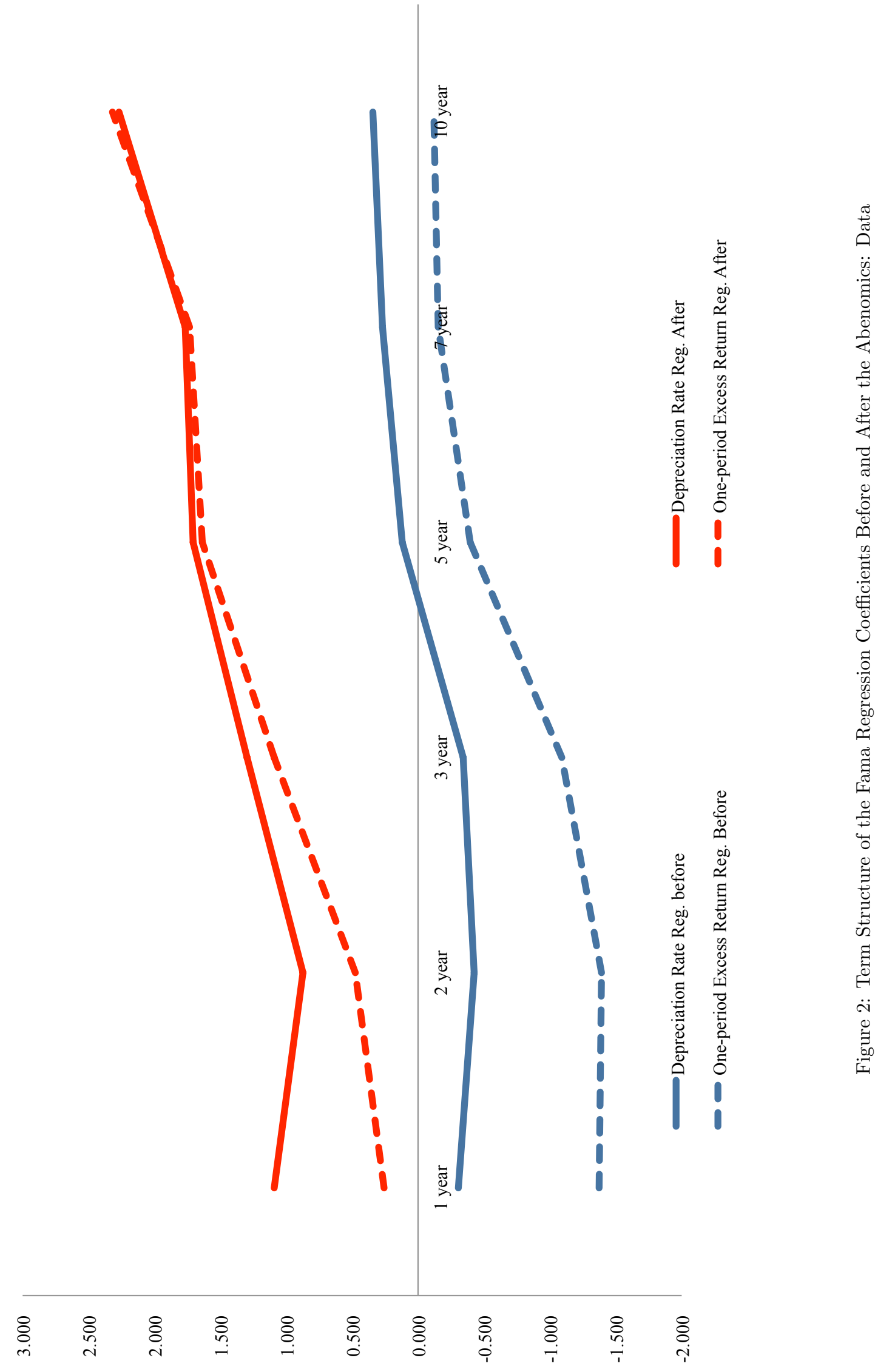




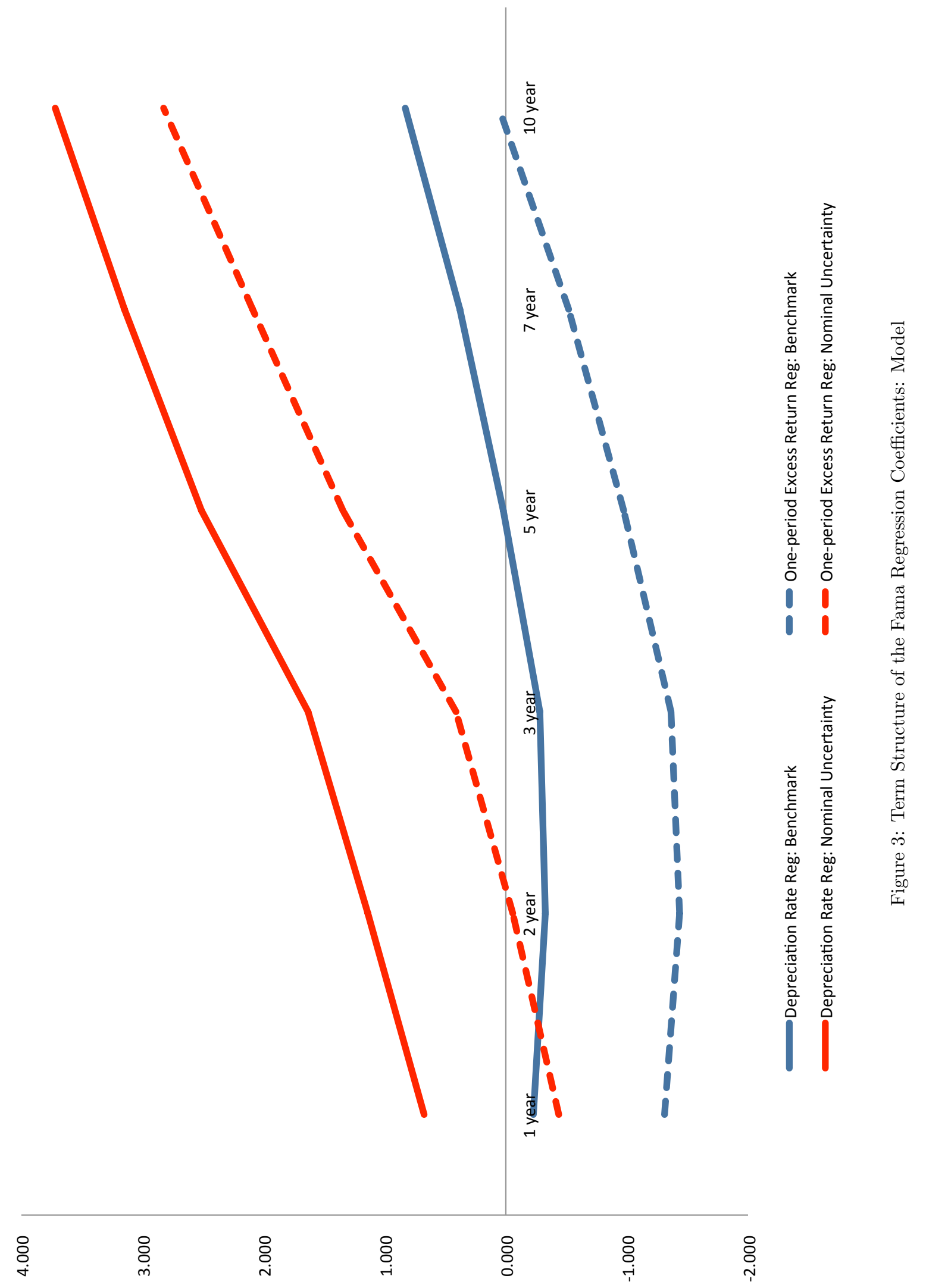




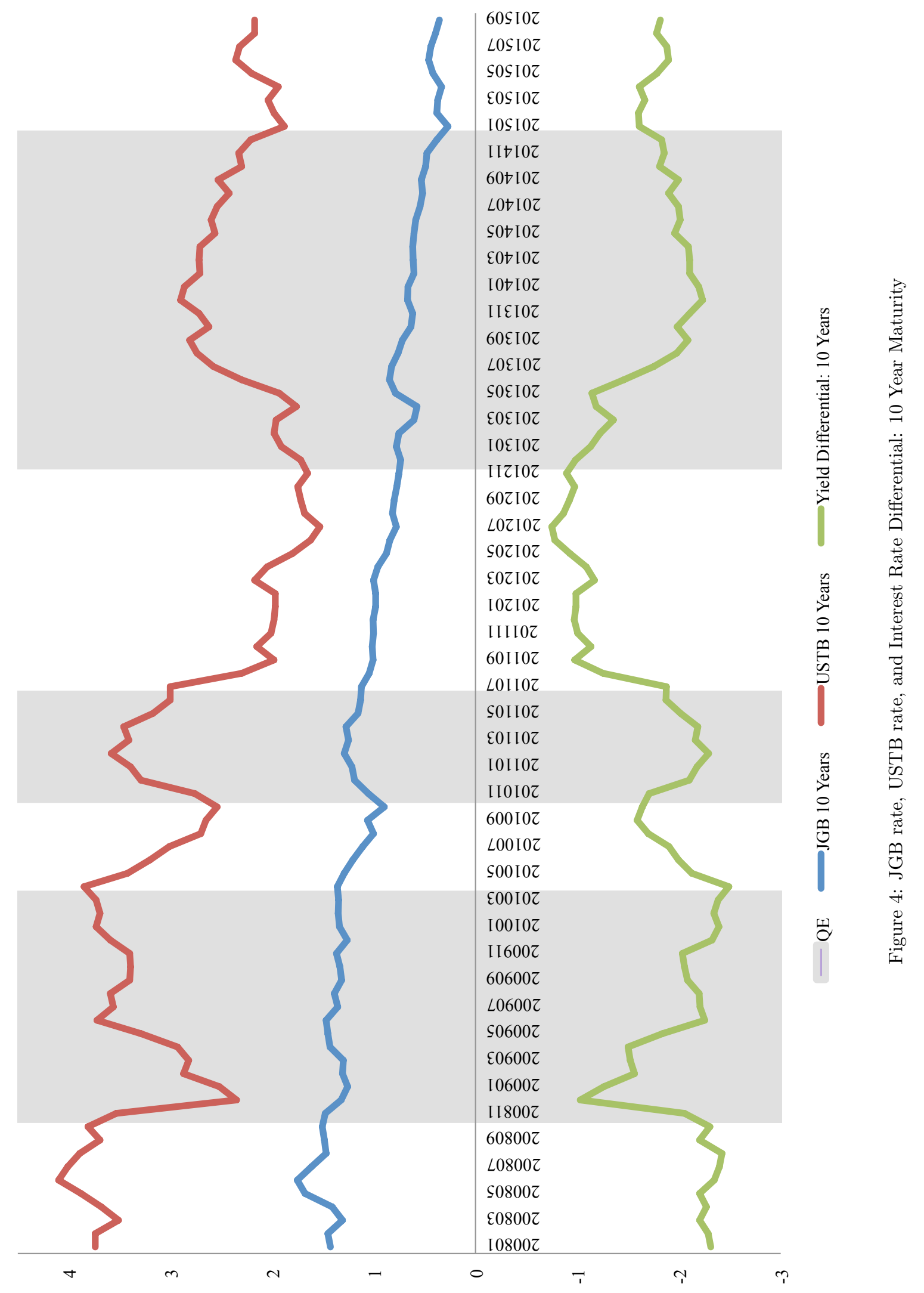




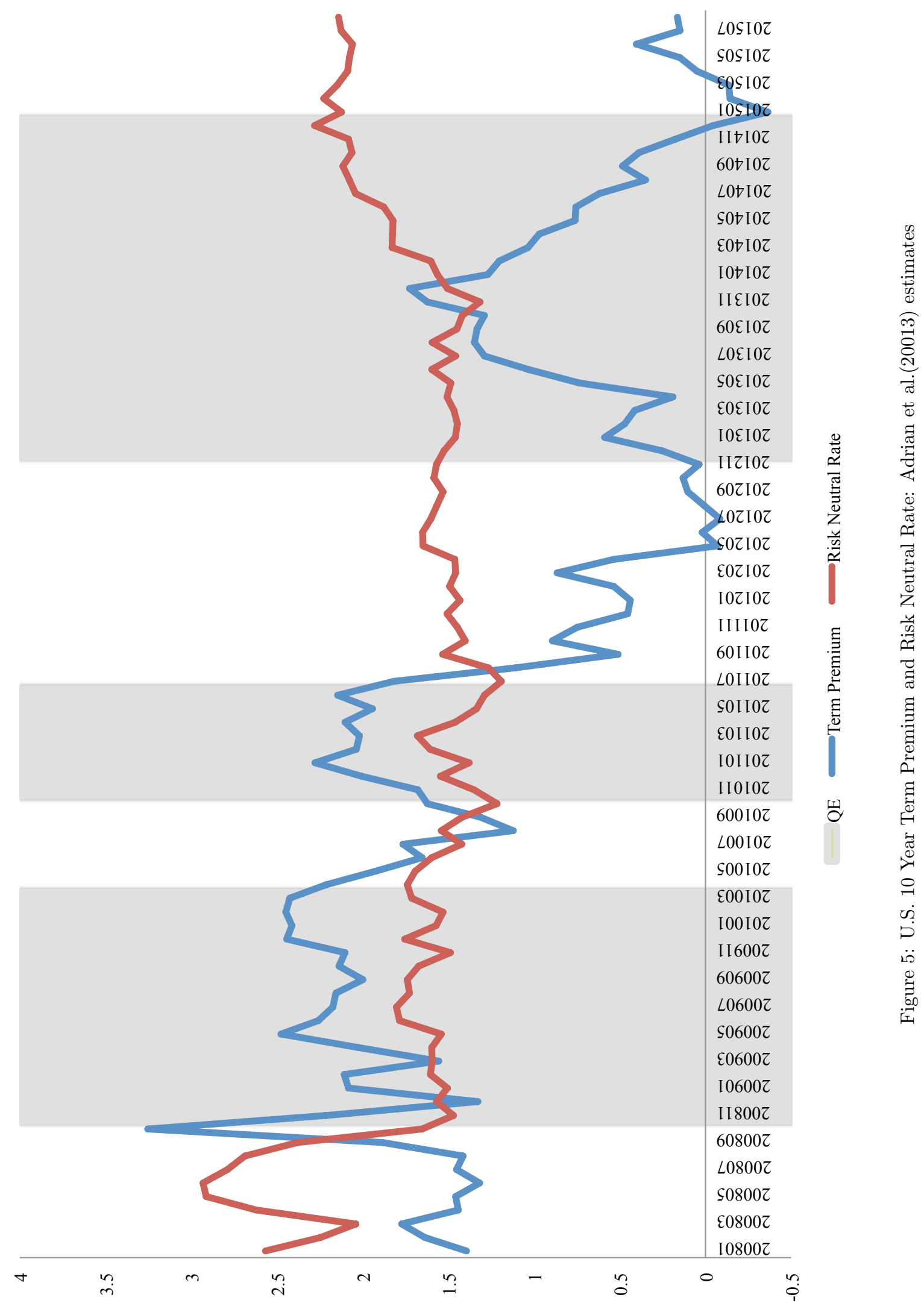

